\title{
Impact of Motivation on Productivity of Craftsmen in Construction Firms in Lagos, Nigeria
}

\author{
Afuye Funso ${ }^{1}$, Letema Sammy ${ }^{1} \&$ Munala Gerryshom ${ }^{2}$ \\ ${ }^{1}$ Department of Environmental Planning and Management, Kenyatta University, Nairobi, Kenya \\ ${ }^{2}$ Centre for Urban Studies, Jomo Kenyatta University of Agriculture and Technology, Nairobi, Kenya \\ Correspondence: Afuye Funso, School of Environmental Studies, Kenyatta University, P. O. Box 43844-00100, \\ Nairobi, Kenya. E-mail: bldrafuye@gmail.com
}

Received: January 13, 2016

Accepted: February 14, 2016

Online Published: March 25, 2016

doi:10.5539/ijef.v8n4p271

URL: http://dx.doi.org/10.5539/ijef.v8n4p271

\begin{abstract}
Motivation has been identified as a useful tool for enhancing productivity. This study aims at determining the impact of motivation on productivity of craftsmen in construction firms in Lagos, Nigeria. Sixteen motivating factors were identified through literature review common to Nigeria construction climate which were used to design questionnaire for the study. A total of 295 questionnaires were administered with 150 filled and returned. This constitute response rate of $50.85 \%$. Productivity rating was done by work study. The mean of motivating factors was correlated with percentage productive hour observed in the sixteen sites surveyed. The outcome indicates that there is positive linear relationship between motivation and productivity. Therefore, motivation influences craftsmen performance in Nigeria construction industry. Further analysis also shows that craftsmen are basically motivated by financial incentives. The paper recommends that financial incentive should be considered for craftsmen in the industry. Moreover, alternative method to working overtime should be employed. The paper concluded that motivation strategy that will enhance productivity should be adopted for workers in the industry.
\end{abstract}

Keywords: labour productivity, motivation, Nigeria, productivity, work measurement

\section{Introduction}

Construction industry is a significant sector in the economic development of any nation; it contributes immensely to gross domestic product (GDP) and employs substantial percentage of her workforce (Yisa, Holt, \& Zakeri, 2000). It is therefore important for her workforce to be motivated. In construction industry, productivity is often measured by workers efficiency (Dozzi \& Abou Rizk, 1993). It is assumed that other factors of production cannot be easily measured; even if measured it is not a reflection of actual work done. It is in line with this that most researches concentrates on ways of improving productivity or factors that can help in achieving productivity improvement (Herzberg, 1968; Smither, 2000 in $\mathrm{Ng}$ et al., 2004; Aiyetan \& Olotuah, 2006). The central role played by labour in the attainment of organisational goal call for the need to adequately compensate them based on values added by individual worker.

Productivity decline has been widely reported in construction industry as occurring world over (Yisa et al., 2000; Adnan, 2009; Adjei, 2009; Kaming et al., 1998 in Fagbenle et al., 2013). In Nigeria, productivity decline has been ascribed to be responsible for time and cost overrun of most projects executed and the cause of low GDP recorded in the sector (Koko et al., 2013). To increase labour effectiveness therefore; there are some factors that need to be addressed, such as motivation of the workforce, safety at work, environmental factors and physical limitation (Dozzi \& Abou Rizk, 1993).

Shashank et al. (2014) in their study grouped factors that cause variation in labour productivity into eight. These groups are: manpower, environmental, material/ equipment, motivation, safety, managerial and quality groups. They concluded that out of these eight groups, motivation group has the highest impact on variation of labour in enhancing productivity. They recommended that managers should make the welfare of their workers a priority through motivation schemes in order for them to put in their best in improving productivity. Kazaz et al. (2008) did similar work in Turkey. They classified productivity factors into four groups. These groups of factors include organisational, economic, physical and socio-psychological, and motivational factors. The second most 
important factor after organisational factor from their findings is motivational factor. This underscores the role of motivation in ensuring productivity increase. It is on this premise therefore that this study addresses the impact of motivation on craftsmen productivity in Nigeria.

\section{Study Objectives}

1) To identify motivation factors influencing construction craftsmen productivity in Lagos, Nigeria.

2) To determine the relationship between motivation and productivity of craftsmen in construction firms in Lagos, Nigeria.

\section{Literature Review}

\subsection{Motivation}

Motivation is defined as drive within a person that is responsible for the extent, course and diligence of efforts expended at work (Anthony, 2011). Machiavelli (1512) in Hogget and Kurako (1991) said managers should work to ensure that work crew is unified within the organisation through rewards to friends and followers to ensure their continuous allegiance. It follows from the above that work motivation serves two basic purposes: firstly, to ensure productivity within the work setting and secondly, to enlist workers unity and loyalty through rewards such that effort that will lead to higher productivity is expended.

Motivation theory has been evolving, it is classified into traditional and modern (Graham \& Weiner, 1996). Traditional theories such as hedonism, instinct, behaviourism, and reinforcement are construed as traditional because of their desire to confirm propositions about psychological events in terms of how they initiate behaviour in man. They were based on natural tendency to initiate behaviour in a way desired, hence the acronym traditional theory (Graham \& Weiner, 1996; Smelser \& Bates, 2001). The summary of these theories is that if workers receive positive reinforcement for an action, such as praise, such behaviour will be repeated. However, if negative reinforcement is received such behaviour will be dropped.

This they argued can be influenced by culture, state of mind and environment. Traditional theory was discredited because it cannot be scientifically proved. This heralds the advent of scientifically based theory led by Tailor and the beginning of modern motivation theory (Petri, 2014). Nevertheless, the traditional theory of motivation was able to prove the importance of reward to productivity improvement, and that behaviour is a product of need or desire. The advent of industrial revolution brought about growth of industries and shortage of labour. The industrialists were concerned with how to increase productivity, workers efficiency and maximize profit (Nzibo, 1988; Steers et al., 2004). They argued that previous theories according to Smelser and Bates (2001) only succeeded in generating definitions and descriptions without definite approach to need assessment. It also failed to provide answer to the conditions that are responsible for activating a given need. The outcome of the research produced increase in productivity. Recommendations on the need to train workers, payment to workers based on performance, and job redesign were made. Taylor also postulated that workers will only be motivated by increase in wages and salary.

However, the study overlooked workers desire for job satisfaction, social interaction, and good work environment (Steers et al., 2004; Nzibo, 1988). The work of Taylor brought about increase in workers' pay and performance improvement yielding profit to the industrialist. However, this break-through did not last long. This is because the industrialist wanted to drive workers like slaves without commensurate increase in incentive scheme and motivation. This resulted in formation of unions to resist such move. This led to another movement of social scientist called human relations movement. This movement advocated that treating man as machine and taking financial incentive as motivator is responsible for low morale and poor output of workers, hence the need for change of approach. Mayo recommended that work should be seen as a group activity hence, workers must be recognised, their security ensured and sense of belonging promoted. They argued further that workers attitude and effectiveness are determined by social demands both within and outside the place of work. This work came under strong criticism for not determining the type of supervision, lack of consideration for environmental factors, refusal to acknowledge conflict of interest between workers and managers, not correlating the relationship between workers need and organisational goals. Nevertheless, the effect of this study heralded the advent of human relations in industrial setting and subsequent research built on it.

The perceived shortcomings of this human relations approach brought about contemporary theory of motivation. This was grouped into content and process theories (Aiyetan \& Olotuah, 2006). Content theory focussed on factors that can motivate workers while process theory focuses on what leads to motivation (Ruthankoon \& ogunlana, 2003 in Navarro, 2009: Steers et al., 2004). The major contributors to content theory are Maslow, Herzberg, and McClelland. Major theories under process are expectancy theory, goal setting and equity theory. 
Herzberg in his theory identified some factors that can motivate workers and enhance productivity improvement among which is reduction in working hour, salary increase, bonus, training, communication, job participation, appreciation of efforts, advancement, satisfaction from work, good supervision and job security (Herzberg, 1968). Some of these factors constituted the variables that were used for this study. There is no need for further discussion of other theories mentioned above because their review is available elsewhere (Navarro, 2009: Steers et al., 2004; Aiyetan \& Olotuah, 2006).

\subsection{Productivity}

Productivity is significant to economic development of any nation (PWC, 2013). It is the measure of the wealth of a nation and the well being of the people. Productivity according to oxford Advanced Learners Dictionary $8^{\text {th }}$ edition (2010) is defined as the rate at which worker, organisation or nation produces goods and services, the quantity produced compared to the amount of time, labour and money expended in producing them. The rate here refers to the speed at which goods or building facilities are produced. PWC (2013) observed that the less the time spent in producing building facility, the more the money that will be saved. Impliedly, the higher the construction productivity, the less the construction cost. PWC (2013) identified three measures of productivity which are labour, capital and multifactor productivity.

Labour productivity is the total construction output to labour input. Capital productivity is the effectiveness with which money is used to provide goods and services, while multifactor productivity is the output derived from the combination of labour and capital as input. Dozzi and Abou Rizk (1993) ; Lawal and Kolawole (2004) identified two measures of labour productivity. They are:

- The effectiveness at which labour is utilized in construction activity.

- The efficiency at which labour executes a given task within a given period of time.

The effectiveness at which labour is used is determined by other inputs such as technology, methodology adopted in construction process, and design modifications by way of making design better to meet client' need. Dozzi and AbouRizk (1993) argued further that the interest of contractors is on how efficiently labour is utilized. This is significant in the sense that quotations are submitted by contractors based on quantity of work to be done. To measure productivity therefore, consideration should be giving to what is produced per person within a given period of time. In essence, what is produced should be compared to the time, and number of persons required in its production. This can be done by indirect measurement of activities through observation. Dozzi and AbouRizk (1993) identified the following methods as being suitable for measuring effectiveness and productivity of work crew:

\section{1) Field rating}

This is a measuring technique that makes use of observation of work crew, and categorise them as either working or not at the period of observation. The number of observed working time is divided by the total number of observations made and converted to percentage to get the percentage productive time. However, ten percent of the productive hour is added to percentage productive hour obtained to compensate for supervisor input to productivity process.

\section{2) Work sampling}

Work sampling takes an observation of working crew and categorise them as productive, semi-productive or not productive. This decision will be made based on what he finds the crew doing at the time of observation. The percentage of productive, semi and non productive time can be calculated. The percentage of productive time should exceed thirty percent for the crew to be classified as productive.

\section{3) Five minute rating}

This method is carried out by observing an activity for a period of time pre-determined by the observer. Five minutes is usually adopted as sufficient to make meaningful observation. Data collection form is required to record observations made. The identified crew to be observed are entered into the form with the required time interval at the extreme left. Then, observation will be made for the period indicated. If the crew is active for at least half of the time, the column will be marked X, if otherwise, it will be left blank. When the desired number of observation has been made, the total number of productive time is calculated and converted to percentage.

\section{Research Methodology}

Two sets of data were collected for this study. The first was through questionnaire survey to craftsmen in large and medium size construction firms in Lagos, Nigeria. They were asked to rank motivating factors on a Likert scale of 1-5, with 1-indicating very low, 2-low, 3-average, 4-high and 5-very high in accordance with its 
influence on their performance. Their productivity level was measured using five minute field rating method. This method was adopted because the study is interested in craftsmen efficiency and not on what constitute delay. Seventeen observations were made in each of the sixteen sites surveyed, making a total of 272 observations. The categorisation of firms was made as identified by Inuwa (2014) that large sized construction firms has capacity to execute contract of fifty million naira and above $(\$ 284,000)$, while medium sized has capacity to execute fifty million naira and below.

Two hundred and ninety five questionnaires were administered with the help of research assistance using purposive sampling technique. However, the number filled and returned is 150 which constitute response rate of $50.85 \%$. Descriptive statistics was used to compute the mean of factors which assisted in the ranking. Thereafter, the mean of motivation of craftsmen and the average productive hour in each of the sites surveyed were correlated using Spearman ranked correlation coefficient. This was used to determine the relationship that exists between motivation and productivity. SPSS version 17 was used to carry out the analysis.

\section{Results}

\subsection{Motivating Factors Influence of Craftsmen}

Craftsmen were asked to rank motivating factors according to its influence on their performance (Table 1).

Table 1. Motivating factors influence on craftsmen

\begin{tabular}{cccc}
\hline Factors & Mean & Standard Deviation & Rank \\
\hline Safety provision & 3.94 & .58 & 1 \\
Good salary & 3.89 & .49 & 2 \\
Bonus & 3.87 & .62 & 3 \\
Appreciation of efforts & 3.82 & .68 & 4 \\
Recognition by authority & 3.70 & .77 & 5 \\
Skill development & 3.68 & .70 & 6 \\
Challenging work & 3.65 & .79 & 7 \\
Opportunity to be promoted & 3.64 & .68 & 8 \\
Job security & 3.63 & .72 & 9 \\
Good supervision & 3.63 & .72 & 9 \\
Cooperation from others & 3.52 & .56 & 11 \\
Satisfaction at work & $\mathbf{3 . 4 8}$ & $\mathbf{. 6 5}$ & $\mathbf{1 2}$ \\
Good work environment & $\mathbf{3 . 4 3}$ & $\mathbf{. 6 9}$ & $\mathbf{1 3}$ \\
Freedom at work & $\mathbf{3 . 1 7}$ & $\mathbf{1 . 0 5}$ & $\mathbf{1 4}$ \\
Taking part in decision & $\mathbf{3 . 0 9}$ & $\mathbf{. 6 8}$ & $\mathbf{1 6}$ \\
Working overtime & $\mathbf{2 . 8 5}$ & $\mathbf{9 3}$ &
\end{tabular}

The outcome of the analysis indicates that craftsmen are mostly influenced by safety provision with value of 3.94 and SD of .58. The second most ranked motivator is good salary with mean score of 3.89 and SD of .49, an indication of strong agreement among respondents. The third most ranked motivator is bonus with mean score of 3.87 and SD of .62. Appreciation of efforts is the forth motivator with mean score of 3.82 and SD of .68. The least motivator is working overtime with mean score of 2.85 and SD of .93.

\subsection{Relationship between Motivation and Productivity}

The percentage productive hour as observed in all the sites surveyed are listed in the order indicated below from company (CP) 1- CP16: 52.94\%, 64.71\%, 58.82\%, 52.94\%, 47.06\%, 52.94\%, 58.82\%, 52.94\%, 58.82\%, 64.71\%, $52.94 \%, 52.94 \%, 70.59 \%, 64.71 \%, 58.82 \%$, and $64.71 \%$ respectively.

Total numbers of observations made is 272 ,

Total number of productive hour is 158

Percentage productive hour observed $=\frac{\text { Total No.of productive hr }}{\text { Total No.of observations made }} \times 100=158 / 272 \times 100$

Average productive hour $=58.09 \%$

The mean score of motivating factors influence on craftsmen as indicated in Table 1 was correlated with the productive hour obtained in all the companies surveyed. The null hypothesis for the study states that there is no relationship between motivation and productivity. 
Preliminary analysis was done to guide against violation of the assumptions of normality, linearity and homoscedasticity through the scatter plots. The output of the correlation analysis is indicated in Table 2 . The results show that there is a strong positive relationship between motivation and productivity as reflected in the $\mathrm{r}$ value of .947 and $\mathrm{p}<.005$.

The study went further to determine the variance (coefficient of determination) between the two variables. These two variables share $89.68 \%$ of their variance. Impliedly, productivity helps to explain $89.68 \%$ of the variance in supervisor' scores on the motivation scale. This is an indication that motivation has high impact on productivity. This relationship is equally significant at $p<.05$, which means there is $95 \%$ confidence in this result. Since the results of the analysis indicates r-value of .947 , p- value of .000 which is less than .05 . The null hypothesis is rejected and alternative hypothesis that states that there is a relationship between motivation and productivity upheld.

Table 2. Correlation between motivation and productivity

\begin{tabular}{ccc}
\hline & Motivation & Productivity \\
\hline Motivation Pearson Correlation & 1 & $.947^{* *}$ \\
Significant (2-tailed) & & .000 \\
$\mathrm{~N}$ & 16 & 16 \\
Productivity Pearson Correlation & $.947^{* *}$ & 1 \\
Significant (2-tailed) & & .000 \\
\hline $\mathbf{N}$ & $\mathbf{1 6}$ & $\mathbf{1 6}$ \\
\hline
\end{tabular}

\section{Discussions}

The safety of craftsmen is the most ranked motivator, an indication of its importance to their performance, hence should be ensured by company management. This is their major concern and a source of motivation. Construction industry is one of the accident prone industries and ranked third after mining and fishing industries, hence the need to ensure the safety of craftsmen. The second to fourth motivators can be said to be financial incentive, because bonus and appreciation of efforts are viewed as such. It will suffice to conclude that craftsmen are motivated mostly by financial incentive. The fifth most ranked motivator is recognition by authority. Craftsmen value their relationship with superiors and view it as acknowledgement of efforts. The relationship between motivation and productivity also indicates that one influences the other. In other words the more craftsmen are motivated, the more the efforts expended towards productivity attainment. The outcome of the analysis can best be summarised that the more workers are motivated, the more the level of continuous improvement attained in productivity all other factors being constant. Locke in https: //www.nbrii.com in his study affirms that financial reward contributes $30 \%$ to productivity improvement. The use of financial reward should therefore be applied for craftsmen in Nigeria construction industry. Moreover, following the influence of motivation on productivity, motivation strategy that will impact on productivity should be adopted by construction firms in Nigeria. The results of the analysis also indicate that overtime is the least ranked motivator. This is a reflection of lack of acceptance of overtime among craftsmen. Hence, alternative measure should be sought to get work done within the time schedule.

\section{Conclusion}

The paper is on the impact of motivation on construction workers productivity in Lagos, Nigeria. The research outcome has been able to establish that motivation has positive impact on workers' productivity. It will therefore be of benefit to the industry if motivating strategy that can enhance productivity improvement is adopted; most especially the use of financial incentive should be considered for craftsmen in the industry.

\section{References}

Adjei, E. A. (2009). Motivational Strategies to Improve Productivity in the Construction Industries in Ghana. An unpublished M.Sc Thesis of the Department of Building Technology, Kwame Nkrumah University of Science and Technology, Kumasi, Ghana.

Adnan, E., Sherif, M., \& Saleh, A. (2009). Factors Affecting the Performance of Construction Projects in the Gaza Strip. Journal of Civil Engineering and Management, 15(3), 269-280. http://dx.doi.org/10.3846/1392-3730.2009.15.269-280

Anthony, B. (2011). How to improve motivation. Retrieved from http://www.Bookboon.com 
Ayeitan, A. O., \& Olotuah, A. O. (2006). Impact of Motivation on Workers Productivity in the Nigerian Construction Industry. Proceedings $22^{\text {nd }}$ ARCOM Conference 4- $6^{\text {th }}$ September, 2006. Birmingham, U.K. Association of Research in Construction Management, pp. 239-248.

Dozzi, S. P., \& AbouRizk, S. M. (1993). Productivity in Construction. Institute for Research in Construction, pp. $16-24$.

Fagbenle, O. I., Ogunde, A. O., \& Owolabi, J. D. (2011). Factors Affecting the Performance of Labour in Nigerian Construction Sites. Mediterranean Journal of Social Sciences, 2(2), 2011.

Graham, S., \& Weiner, B. (1996). Theories and Principles of Motivation. In D. C. Berliner, \& R. C. Calfee (Eds.), Handbook of Educational Psychology. New York: Simon and Schuster Macmillan.

Herzberg, F. (1968). One More Time: How do You Motivate Employees? Harvard Business Review, 1968.

Hodgetts, R. M., \& Kuratko, D. F. (1991). Management (3rd ed.). Harcourt, Florida, USA.

Inuwa, I. I. (2014). Investigating Project Planning in Construction Procurement: The Case of Nigerian Indigenous Contractors. Ph.D. Thesis, Jomo Kenyatta University of Agriculture and Technology, Nairobi, Kenya.

Kazaz, A., Manisali, E., \& Ulubeyli, S. (2008). Effect of Basic Motivational Factors on Construction Workforce Productivity in Turkey. Journal of Civil Engineering and Management, 14(2), 95-106. http://dx.doi.org/10.3846/1392-3730.2008.14.4

Koko, R. A., Afuye, F., \& Demide, N. I. (2013). Causes of Time Overrun of Education Trust Fund Building Projects in North Central Nigeria. Journal of Research in National Development, 11(1), 183-188.

Lawal, P. O., \& Kolawole, J. O. (2004). Productivity Appraisal of the Nigerian Public Service Construction Craftsmen. Nigerian Journal of Construction Technology and Management, 5(1), 15-24.

Navaro, W. (2009). A Review of Maslow's, Herzberg and Vroom in the Construction industry over the Past 25 years. Proceedings of $25^{\text {th }}$ Annual ARCOM Conference, 7-9 September 2009, Nottingham, UK.

Ng, S. T., Skitmore, R. M., Lam, K. C., \& Poon, A. W. C. (2004). Demotivation Factors Influencing the Productivity of Civil Engineering Projects. International Journal of Project Management, 139-146. http://dx.doi.org/10.1016/S0263-7863(03)00061-9

Nzibo, Y. A. (1988). The Evolution of the Various Theories on the Subject of Motivation. The Paper Presented to the MBA Class, Lansdowne Independent College, London, June.

Petri, H. L. (2014). Motivation Behaviour. Encyclopaedia Britanica htm.

PWC. (2013). Reconstructing Productivity: Productivity in the Construction Industry. Retrieved from http://www.pwc.com/structure

Shashank, K., Supata, H., Kabin, D., \& Nath, P. (2014). Analysis of Key Factors Affecting Variation of Labour Productivity in Construction Projects. International Journal of Emerging Technology and Advanced Engineering, 321-327.

Smelser, N. J., \& Bates, P. B. (2001). Motivation, Learning, and Instruction. International Encyclopedia of the Social and Behavioural Sciences, 15.

Steers, R. M., Mowday, R. T., \& Shapiro, D. L. (2004). Introduction to Special Topic Forum: The Future of Work Motivation Theory. Academy of Management Review, 29(3), 379-387. http://dx.doi.org/10.2307/20159049

Yisa, S. B., Holt, G. D., \& Zakeri, M. (2000). Factors Affecting Management Motivation in the Iranian Construction Industry: A Survey of Site Managers. Association of Researchers in Construction Management, 2, 465-472.

\section{Copyrights}

Copyright for this article is retained by the author(s), with first publication rights granted to the journal.

This is an open-access article distributed under the terms and conditions of the Creative Commons Attribution license (http://creativecommons.org/licenses/by/3.0/). 